\title{
Torque Analysis of Self-drilling Mini-screws placed with and without a Pilot Drill: A Canine Study
}

\author{
${ }^{1}$ Daniela A Zambon-Fagundes, ${ }^{2}$ David G Kerns, ${ }^{3}$ William W Hallmon, ${ }^{4}$ Eric S Solomon
}

\section{ABSTRACT}

Purpose: The use of temporary anchorage devices (TADs), such as mini-screws, palatal implants and mini-plates, has become a popular treatment option in orthodontics. The objectives of this study were: (1) to compare the success rates of self-drilling mini-screws placed with or without use of a pilot drill, (2) to evaluate the implant placement torque (IPT) of self-drilling miniscrews and (3) to measure the removal torque of self-drilling mini-screws.

Materials and methods: Six American Foxhounds served as subjects in this study. Three OsteoMed self-drilling mini-screws (1.6 $\mathrm{mm}$ diameter and $8 \mathrm{~mm}$ length) were planned to be placed in each side of the mandible between the roots of the teeth canine/premolar 1 (PM1), PM2/PM3 and PM3/PM4. The sites were allocated randomly in: (1) control group-mini-screws placed with pilot drill and (2) test group-mini-screws placed without pilot drill (self-drilling). The implant placement torque (IPT) and the number of turns performed by the mini-screws during placement were measured. After a healing period of 6 weeks, the mini-screws were removed, and the removal torque was measured.

Results: A total of 33 mini-screws were placed in six animals. After 6 weeks, the success rate for the control and test groups were 46.7 and $80 \%$ respectively (difference not statistically significant). There was no statistically significant difference in the terminal mean IPT values and the mean number of turns for failed and successful mini-screws. The difference between the mean IPT values at the 3rd turn during mini-screw placement in the successful and failed mini-screws (5.56 and $14.03 \mathrm{Ncm}$ respectively) was statistically significant $(p<0.01)$.

Conclusion: There was no statistically significant difference in the success rate between self-drilling mini-screws that did or did not have osteotomies (46 vs $80 \%$ respectively). However, the IPT at the third revolution for successful mini-screws averaged $5.56 \mathrm{Ncm}(p<0.01)$.

Keywords: Orthodontic anchorage, Temporary anchorage devices, Screw, Mini-screw, Dental implants, Placement torque.

How to cite this article: Zambon-Fagundes DA, Kerns DG, Hallmon WW, Solomon ES. Torque Analysis of Self-Drilling Mini-screws placed with and without a Pilot Drill: A Canine Study. J Contemp Dent 2014;4(2):77-86.

\footnotetext{
${ }^{1}$ Assistant Professor, ${ }^{2,4}$ Professor, ${ }^{3}$ Regents Professor (Retired)

${ }^{1-3}$ Department of Periodontics, Baylor College of Dentistry, Texas A\&M University, Dallas, Texas, USA

${ }^{4}$ Department of Administration, Baylor College of Dentistry, Texas A\&M University, Dallas, Texas, USA

Corresponding Author: David G Kerns, Professor, Department of Periodontics, Baylor College of Dentistry, Texas A\&M University, Dallas, Texas, USA, Phone: 2148288140, e-mail: dkerns@bcd.tamhsc.edu
}

\section{Source of support: $\mathrm{Ni}$}

Conflict of interest: None

\section{INTRODUCTION}

Orthodontic anchorage is defined as 'resistance to unwanted tooth movement', and anchorage control is essential for successful orthodontic treatment. Newton's third law of motion states that, for every action, there is an equal and opposite reaction. It is this principle that accounts for reciprocal effects during orthodontic treatment that must to be evaluated and controlled in order for the treatment goals to be achieved. For years, orthodontists have attempted to improve the method of resisting the forces (anchorage) applied for tooth movement in order to minimize undesirable effects.

A temporary anchorage device (TAD) is a device that is temporarily fixed to the bone with the objective of enhancing orthodontic anchorage, and is subsequently removed after the completion of its function during orthodontic treatment. ${ }^{1}$ The term TAD can refer to implants, palatal implants, screws, pins, mini-implants, micro-implants, mini-screws, micro-screws, onplants and mini-plates that are placed for the specific purpose of providing orthodontic anchorage and that are often removed after the completion of orthodontic treatment. ${ }^{2}$ Dental implants placed for the purpose of supporting a prosthesis that have been used temporarily for orthodontic anchorage, are not considered TAD since they are not normally removed after orthodontic treatment. ${ }^{1}$ It appears that there is no general consensus in the literature on specific terminology, as a result different authors have used various terms for the anchorage devices. In the current study, the terminology used will correspond to that described in referenced publications, and the term 'mini-screw' will be used in reference to the devices used in this specific study.

Of all the fixed anchorage devices, mini-screws are the least invasive and most conservative in terms of placement and removal. ${ }^{3}$ Mini-screws have the advantages of minimal anatomic limitation for placement (greater number of implant sites and indications), lower cost, simpler placement and orthodontic connection, less discomfort after implantation and easier removal after treatment. ${ }^{4-6}$ Initially, screws which were originally used for osteosynthesis were used as devices for orthodontic anchorage. Subsequently, several companies developed more versatile mini-screw systems of varying dimensions designed specifically for orthodontic 
anchorage. Although mini-screws have been used extensively in orthodontic treatment, there is still limited data available related to the establishment of a defined protocol or the healing interval required prior to loading. ${ }^{7}$

Mini-screws have a higher failure rate when compared to traditional dental implants. Miyawaki et al and Cheng et al have reported that the success rates for mini-screws were 83 to $89 \%{ }^{8,9}$

There are considerable literature available providing protocols to assist dentists in placing and restoring endosseous dental implants. Current dental literature has not provided a definitive answer regarding a recommended healing period before orthodontic loading mini-screws. The orthodontist currently determines when to load, based on the subjective evaluation of the bone quality determined by the clinician at the time of mini-screw placement. It would be beneficial for clinicians to be able to make accurate predictions about the anticipated success of mini-screws at the time of surgical placement.

Friberg et al (1999) found a statistically significant correlation between implant placement resistance and bone density values of the prepared site and concluded that methods of placement torque measurements for evaluation of bone quality appear to be reliable. ${ }^{10}$ The interface characteristic between implant and bone can be correlated to the implant placement torque (IPT) at the time of mini-screw placement. It has been hypothesized that a threshold IPT value exists that could be used to predict the chances of success of the mini-screws. ${ }^{11,12}$

Chen et al (2006) examined the removal torque of miniscrews, exploring the correlation between this variable and other clinical variables. Removal torque has been considered an indicator of osseointegration for dental implants. Mean removal torque was $1.10 \mathrm{~kg} \mathrm{~cm}(10.1 \mathrm{Ncm})$ and removal torques for $50 \%$ of the mini-implants were greater that $0.87 \mathrm{~kg} \mathrm{~cm}(8.7 \mathrm{Ncm})$. In their study, the site of implantation (maxilla or mandible) and mini-screw length were important factors associated with removal torque. It was concluded that although an excessive torque in a counterclockwise direction might loosen the mini-screws, their ability to function as anchors for tooth movement persisted throughout the course of orthodontic treatment. ${ }^{13}$

Some mini-screw companies claim that it is not necessary to use a pilot drill for the osteotomy in order to facilitate placement of mini-screws and that they should be used either in a self-taping or self-drilling fashion. ${ }^{14,15}$ With a 'nonselftapping' (or pre-tapped) screw, a pilot hole is drilled, and a surgical tap is used to create threads in the bone. A 'selftapping' screw has a threaded body and a tapered furrow at the tip that cuts a thread in the bone and a surgical tap is usually not necessary. A 'self-drilling' screw resembles a corkscrew with a sharp tip and a threaded body. It requires no pilot drilling and works like a cutting flute, expelling bone debris onto the surface. ${ }^{14,16}$ Special features of the self-drilling screws include a tapering tip, conical shaft and smaller cutting flute, when compared to the self-tapping screw. ${ }^{17}$ From a practical perspective, the self-drilling concept involves a radial displacement of bone by the conical tip of the screw, which could potentially damage the bone. ${ }^{17}$

In the current study, the terminology used will correspond to that described in referenced publications, and the term 'mini-screw' will be used in reference to the devices used in this specific study. The first objective of this study was to evaluate the success rates of self-drilling mini-screws implants placed with or without use of a pilot drill using the $\mathrm{OMI}^{\mathrm{TM}}$ (Orthodontic Anchor System, OsteoMed Corporation, Addison, TX). The second objective was to evaluate the relationship between the success rate and the IPT of self-drilling mini-screws. The third objective will be to measure the removal torque of the self-drilling mini-screws at 6 weeks postplacement.

\section{MATERIALS AND METHODS}

Six, healthy male, American Foxhounds (Canis familiaris) weighting 20 to $30 \mathrm{Kg}$ and approximately 2 years old served as subjects for this study. The study protocol was reviewed and approved by the Baylor College of Dentistry, Institutional Animal Care and Use Committee.

The self-drilling mini-screw system used in this study $\left(\mathrm{OMI}^{\mathrm{TM}}\right.$ OsteoMed Corporation, Addison, TX) had dimensions of $1.6 \mathrm{~mm}$ (diameter) and $8 \mathrm{~mm}$ (length) and was made of grade 5 titanium. The mini-screw has a tapered shape and the thread pitch is $0.762 \mathrm{~mm}$. After analyzing a foxhound skull and the radiographs, the following interdental areas were selected for the placement of mini-screws: between the roots of the canine and PM1 (premolar 1), PM2 and PM3, and PM3 and PM4. Three mini-screws were planned to be placed in the premolar areas of the mandible on each side, with a total of six mini-screws per animal, resulting in a total of 36 mini-screws (Figs 1 and 2). A computergenerated randomization of the control and test sites to be used for the mini-screws placement. In the control group, mini-screws were to be placed with pilot drill and, in the test group, mini-screws were to be placed without pilot drill.

\section{Surgical Procedure}

The animals received no food or water 12 hours (NPO) prior to surgery. The animals were intramuscularly sedated to effect with ketamine $(2.2 \mathrm{mg} / \mathrm{kg} / \mathrm{IM})$ and xylazine $(0.22 \mathrm{mg} /$ $\mathrm{kg} / \mathrm{IM})$. Each animal had radiographs of the planned surgical sites taken on the mandible to aid in locating anatomic structures before placement of the mini-screws.

The surgeries were performed in aseptic conditions with each animal sedated with ketamine $(2.2 \mathrm{mg} / \mathrm{kg} / \mathrm{IM})$ and 


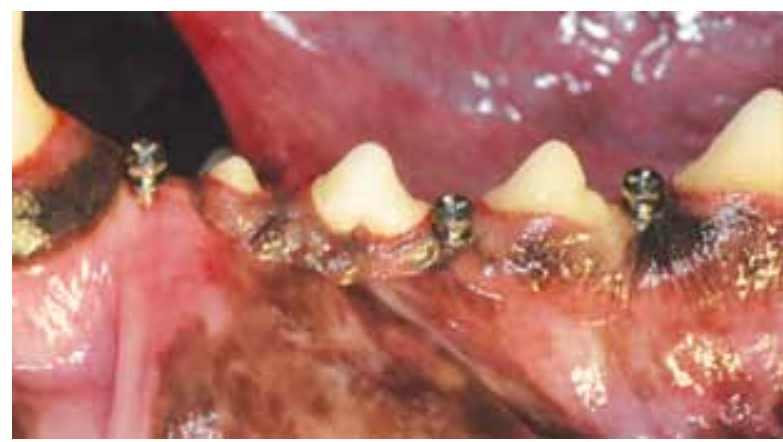

Fig. 1: Dog 5-left side at micro-screw placement

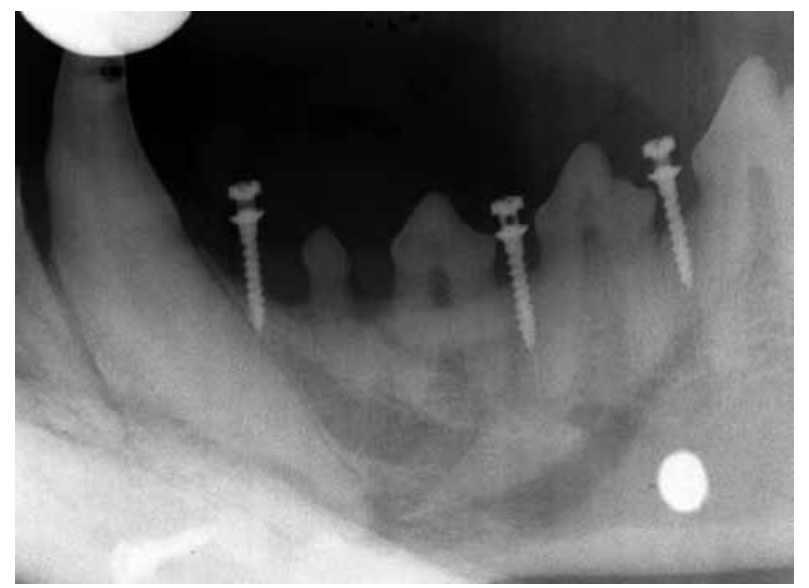

Fig. 2: Dog 5-radiograph of left side at micro-screw placement

xylazine $(0.22 \mathrm{mg} / \mathrm{kg} / \mathrm{IM})$. Lidocaine $\mathrm{HCl} 2 \%$ with epinephrine $(1: 100,000)$ was used as the local anesthetic. During the sedation, the vital signs were monitored and recorded by a trained animal technician.

For the control sites, a pilot hole was drilled through the soft tissue into cortical bone with a $1.3 \mathrm{~mm}$ pilot drill. The self-drilling mini-screws were placed into the pilot hole with a mini-screw driver provided by the manufacturer (Taperlock ${ }^{\mathrm{TM}}$ Screwdriver Body). The OsseoCare ${ }^{\mathrm{TM}}$ Drilling Unit (Brånemark System) was used to record torque and revolution data (Figs 3 and 4). The OsseoCare ${ }^{\mathrm{TM}}$ Drilling Unit can be set to limit torque value. For this study, the maximum torque value was set at $30 \mathrm{~N} / \mathrm{cm}(30 \mathrm{rpm})$. This is the maximum torque that the manufacturer recommends to not exceed breakage of the mini-screw. External irrigation with saline was used as a cooling system during the pilothole drilling and mini-screw placement in order to avoid overheating of the bone.

For test sites, no pilot drill was used to create an osteotomy (Fig. 5). The self-drilling mini-screws were placed through the soft tissue and screwed into bone. Every effort was made to avoid damage to the tooth roots or adjacent vital structures. All screws achieved a mechanical lock at the time of placement. Radiographs were taken postoperatively to evaluate the position of the mini-screws.

After the placement of the mini-screws, the animals were kept on a soft diet. For postoperative pain control, buprenorphine $(0.02 \mathrm{mg} / \mathrm{kg})$ was given subcutaneously (SQ) immediately postoperatively. Ibuprofen was administered by mouth mixed into dog soft food for 3 days postoperatively.

\section{Mini-screws Removal}

After a healing period of 6 weeks, ${ }^{18,19}$ the self-drilling mini-screws were removed and removal torque measured. A different torque control unit (Nobelpharma Torque Controller $^{\mathrm{TM}}$, Brånemark System ${ }^{\circledR}$ ) was used for mini-screw removal since the OsseoCare ${ }^{\mathrm{TM}}$ Drilling Unit does not measure the torque values in the reverse mode. The Nobelpharma Torque Controller ${ }^{\mathrm{TM}}$ can be set at 10, 15, 20, 32 and $45 \mathrm{Ncm}$ in the reverse mode. The removal torque for this study was $10 \mathrm{Ncm}$.

\section{Statistical Analysis}

The data were entered and analyzed by the SPSS software (SPSS Inc., Chicago).

The Pearson's chi-square analysis was performed to compare the success rate of the mini-screws placed with

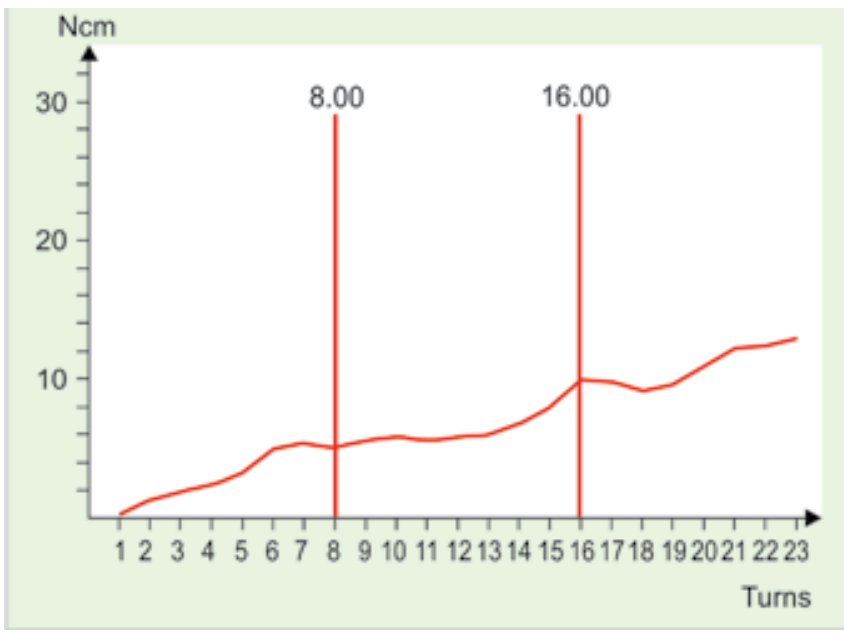

Curve

08010124.sur

Ref. No.

Family Name

First Name

Initials

Date of Birth

Gender

Surgery Date

Location

Fixture Type

Prosthetic Type

Screw Type

Executive

Notes

Selected Torque $\quad: 30 \mathrm{Ncm}$

No. of Turns $\quad: 23.00$

Average $1 / 3 \quad: 3 \mathrm{Ncm}$

Average 2/3 : $7 \mathrm{Ncm}$

Average $3 / 3 \quad: 11 \mathrm{Ncm}$

Fig. 3: Control site: Number of turns and IPT of the pilot drill 
(control) and without (test) previous drilling with a pilot hole. If the mini-screw was present at removal, the miniimplant was determined as a success; when the mini-screw was absent at the removal, it was considered a failure. The differences in the torque values IPT in the success and failure groups were compared using a t-test with a $95 \%$ confidence interval. The difference in the number of turns performed by the screw during placement between the success and failure groups was also compared using a t-test. The results obtained from the various analyses were reported as means, standard deviations and ranges.

\section{RESULTS}

A total of 33 mini-screws were placed. In three sites, miniscrews could not be placed because of anatomic limitations (one dog had an extra premolar and the other two sites were too narrow to accommodate a mini-screw).

In eight sites that were originally planned as test sites, the mini-screws could not be placed to depth with a torque of $30 \mathrm{Ncm}$, so each one was removed and a pilot drill used to allow the mini-screw to be placed to depth. All eight of

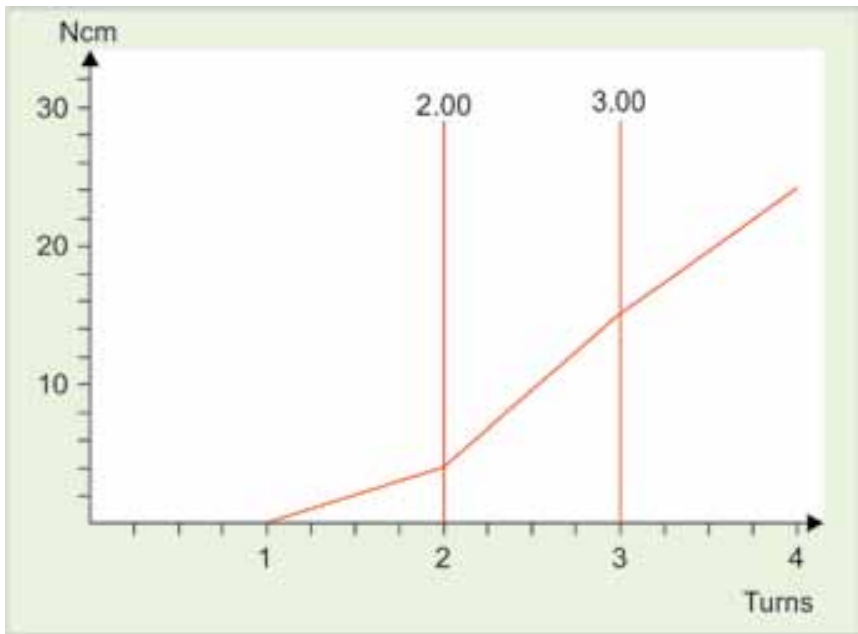

\section{Curve}

08010125.sur

Ref. No.

Family Name

First Name

Initials

Date of Birth

Gender

Surgery Date

Location

Fixture Type

Prosthetic Type

Screw Type

Executive

Notes

Selected Torque

No. of Turns

Average 1/3

Average 2/3

Average 3/3

Fig. 4: Control site: Number of turns and IPT of mini-screw (failure) these mini-screws (designated additional control sites) failed. Consequently, three groups were considered for statistical analysis: group I, the control group (pilot hole), group II, mini-screws that could not be placed to depth, had to be removed and had a pilot hole drilled in order to place miniscrew to depth (additional control group), and group III, the test group (no pilot hole).

During 6 weeks of healing, a total of 18 mini-screws were lost resulting in an overall success rate of $45.5 \%$. Two animals $(30 \%)$ were responsible for 11 of the $18(61 \%)$ mini-screws that failed.

At 6 weeks, group I had seven out of 15 mini-screws present, resulting in a success rate of $46.7 \%$ (Table 1). In group II, all of the mini-screws placed failed ( $0 \%$ success). In the test sites (group III), eight out of the 10 mini-screws were present, resulting in a success rate of $80 \%$. When comparing the success rate between the groups I and III, there was no statistically significant difference, possibly because of the small sample size of the study (see Table 1).

In Table 2, the mean terminal IPT values and the mean number of turns for failed and successful mini-screws are

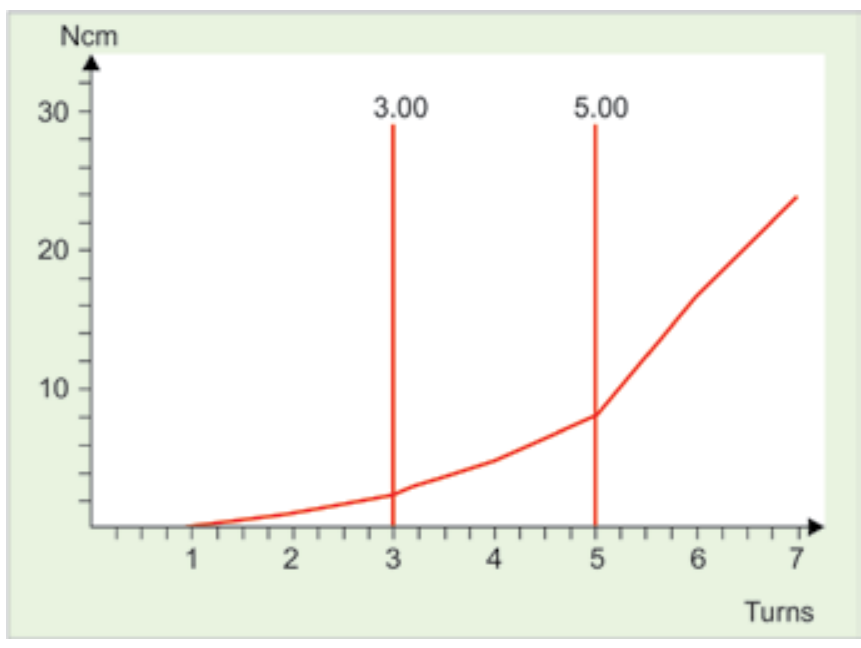

$\begin{array}{ll}\text { Curve } & : \text { 08010121.sur } \\ \text { Ref. No. } & : \\ \text { Family Name } & : \text { Tx } \\ \text { First Name } & : \text { Dog } 5 \\ \text { Initials } & : \\ \text { Date of Birth } & : \\ \text { Gender } & : \\ \text { Surgery Date } & : \\ \text { Location } & : \text { Site } 2 \\ \text { Fixture Type } & : \text { Screw } \\ \text { Prosthetic Type } & : \\ \text { Screw Type } & : \\ \text { Executive } & : \\ \text { Notes } & : \\ \text { Selected Torque } & : 30 \mathrm{Ncm} \\ \text { No. of Turns } & : 7.00 \\ \text { Average } 1 / 3 & : 1 \mathrm{Ncm} \\ \text { Average } 2 / 3 & : 6 \mathrm{Ncm} \\ \text { Average } 3 / 3 & : 20 \mathrm{Ncm}\end{array}$

Fig. 5: Test site: Number of turns and IPT of mini-screw (successful) 
shown. Terminal IPT was the final torque value recorded when the mini-screw was driven to depth or stopped. During the placement of four mini-screws (3 controls and 1 test), the IPT did not record. When the statistical analysis was performed including the groups I (control) and III (test), the mean terminal IPT for the mini-screws that failed was $21.3 \pm 3.27 \mathrm{Ncm}$; for the successful mini-screws, the mean terminal IPT value was $19.76 \pm 5.81 \mathrm{Ncm}$. There was no statistically significant difference in the mean terminal IPT values between the successful and failed mini-screws (see Table 2). The number of mini-screw revolutions during the placement was measured. The mean number of turns for the mini-screws that failed was $5.11 \pm 3.85$; for the successful mini-screws, the mean number of turns was $7.17 \pm 2.51$. There was no significant difference in the mean number of turns between the mini-screws that failed or succeed (see Table 2).

The mean IPT values and the mean number of turns for failed and successful mini-screws were evaluated. During the placement of five mini-screws ( 4 controls and 1 test), the IPT did not record. When the statistical analysis was performed including groups I and II (controls) and the group III (test), the mean terminal IPT for the mini-screws that failed was $20.15 \pm 3.96 \mathrm{Ncm}$; for the successful mini-screws, the mean terminal IPT value was $19.76 \pm 5.81 \mathrm{Ncm}$. There was no statistically significant difference in the mean terminal IPT values between the successful and failed mini-screws (Table 3). The mean number of turns for the mini-screws that failed was $4.50 \pm 2.96$ and the mean number of turns for the mini-screws that succeeded was $7.17 \pm 2.51$. The difference between the mean number of turns between the mini-screws that succeeded and the mini-screws that failed was statistically significant $(\mathrm{p}<0.05)$ (see Table 3$)$.

The mean IPT values at the 3rd turn at the mini-screw placement for failed and successful mini-screws are shown. During the placement of five mini-screws (4 controls and 1 test), the IPT did not record. When the statistical analysis was performed including groups I and II (controls) and the group III (test), the mean IPT at the 3rd turn at the mini-screw placement for the mini-screws that failed was $14.03 \pm 7.39$ $\mathrm{Ncm}$; for the successful mini-screws, the mean IPT value was $5.56 \pm 6.75 \mathrm{Ncm}$. There was statistically significant difference in the mean IPT values at the 3rd turn between the successful and failed self-drilling mini-screws $(p<0.01)$ (Table 4).

\section{DISCUSSION}

Although mini-screw implants have been used as TADs for orthodontic treatment for sometime, their clinical performance, placement and variables affecting the success rate have not been well studied. Many of the publications have been case reports or technical descriptions of the systems available.

Some mini-screw manufacturers claim that it is not necessary to use a pilot drill for osteotomy to facilitate placement of mini-screws. ${ }^{15}$ One of the goals of this study was to compare the stability of self-drilling mini-screws placed with or without an osteotomy (a pilot hole). Self-tapping screws have been generally accepted in craniomaxillofacial surgery, replacing the formerly used pre-tapped screws in osteosynthesis. Advantages of self-tapping screws include more rapid insertion (without use of a tap) and a better grip in thin cortical bone. Heiderman and Gerlack (1999) listed advantages and disadvantages of using self-drilling screws (drill-free screws) for osteosynthesis. Advantages included more rapid insertion, minor risk of stripping bone threads in thin cortical bone and minimal risk of injury to neurovascular structures or tooth roots, since pre-drilling is not necessary. Disadvantages included greater pressure necessary to perforate the bone, screw fractures and screw

Table 1: Success rates of groups I, II and III

\begin{tabular}{ll}
\hline Groups & Success rate (\%) \\
\hline I $(n=15)$ & 46.7 \\
II $(n=8)$ & 0 \\
III $(n=10)$ & 80.0 \\
\hline
\end{tabular}

Group I: Control group; Group II: Additional control group; Group III: Test group; Chi-square; Difference between groups I and III was not statistically significant $(p=0.96)$

Table 2: Terminal implant placement torque mean values and mean number of turns in the successful and failed mini-screws. Analysis including groups I and III

\begin{tabular}{llll}
\hline Groups I and III & $\begin{array}{l}\text { Terminal implant } \\
\text { placement torque }\end{array}$ & & Number of turns \\
\cline { 2 - 2 } & Mean $\pm S D($ Ncm $)$ & Mean $\pm S D$ \\
\hline $\begin{array}{l}\text { Failed mini-screws } \\
(n=9)\end{array}$ & $21.3 \pm 3.37$ & & $5.11 \pm 3.85$ \\
$\begin{array}{l}\text { Successful mini- } \\
\text { screws }(n=12)\end{array}$ & $19.76 \pm 5.81$ & & $7.17 \pm 2.51$ \\
\hline
\end{tabular}

Student t-test; Group I: Control group; Group III: Test group; Difference between the successful and failed mini-screws was not significant for the mean IPT and mean number of turns

Table 3: Terminal implant placement torque mean values and mean number of turns in the successful and failed mini-screws. Analysis including groups I, II and III

\begin{tabular}{llll}
\hline Groups I, II and III & $\begin{array}{l}\text { Terminal implant } \\
\text { placement torque }\end{array}$ & & Number of turns \\
\cline { 2 - 3 } & Mean $\pm S D(\mathrm{Ncm})$ & Mean $\pm S D$ \\
\hline $\begin{array}{l}\text { Failed mini-screws } \\
(\mathrm{n}=16)\end{array}$ & $20.15 \pm 3.96$ & $4.50 \pm 2.96$ \\
$\begin{array}{l}\text { Successful mini- } \\
\text { screws }(\mathrm{n}=12)\end{array}$ & $19.76 \pm 5.81$ & $7.17 \pm 2.51$ \\
\hline
\end{tabular}

Student t-test; Group I: Control group; Group II: Additional control group; Group III: Test group; Difference between the successful and failed mini-screws was not significant for the mean IPT; *Difference between the successful and failed mini-screws was significant for mean the number of turns $(p<0.05)$ 
failures when placing the screws in a nonvertical direction. The self-drilling screw was recommended for central and lateral midface and for the body of the mandible. In the areas where the cortical bone increased in thickness, more pressure was necessary to penetrate the bone. Heiderman and Gerlack also stated that if strong resistance is encountered noticed during insertion of the screw, the insertion should be periodically interrupted for a short time, enabling the bone to adapt to the pressure of the screw. Heideman et al found that the bone/screw contact of drill-free screws (selfdrilling) was higher than that of self-tapping screws. The greater amount of original bone in the threads of self-drilling screws demonstrated that the insertion of this device did not adversely affect the surrounding bone. That study supported the use of these screws for osteosynthesis in areas of thin cortical bone, such as the human midface. ${ }^{20}$

In the current study, the success rate of self-drilling miniscrew was $80 \%$ when a pilot drill was not used compared to $46.7 \%$ when a pilot drill was used. Although this difference was not statistically significant due to small sample size, a trend was seen. The placement of a self-drilling mini-screw when not using a pilot drill was more difficult because of the density of the bone encountered at placement sites in the canine mandible. This was probably the result of differences in the thickness of the cortical bone and type of bone previously described for implant placement sites. ${ }^{21}$ The cortical bone in the posterior mandible of dogs has been reported to be the thickest (mean of $2.41 \mathrm{~mm}$ ) when compared to other areas of the jaws. ${ }^{22}$ Some authors ${ }^{23,24}$ prefer to use a pilot drill only to perforate the bone cortex as opposed to making a channel to guide the mini-screw placement. ${ }^{5,25}$ This should facilitate the placement of the mini-screws mainly in areas where the cortical bone cortical is thick, e.g. the posterior mandible.

Mah and Bergstrand (2005) summarized opinions from the 2004 American Academy of Orthodontics meeting and commented that there is no consensus on the superiority of pilot drilling $v s$ self-tapping temporary anchorage devices. They stated that drilling with 'controlled RPM' is essential to successful outcomes. A recommendation was made to use slow speed (800-1,500 rpm) and low pressure when engaging the bone. ${ }^{2}$ In the present study, a speed of $30 \mathrm{rpm}$ was used for all drills and mini-screws. The unit used only records torque and revolution data at this speed. This added to the difficulty of drilling osteotomies and possibly was accompanied by increase in applied pressure during drilling. This may account for the high failure rates observed in the control group. This afforded an opportunity to evaluate whether or not pilot drill torque could possibly have an effect on the success rate of the mini-screws. When comparing the mean pilot drill torque values for successful and failed mini-screws, no statistically significant difference was observed (Table 5). Therefore, it appears torque values of screw placement and revolutions in cortical plate may be more critical.

Only a few studies have examined the success rates of mini-screws and factors associated with success (Table 6). When used as prosthetic abutments, the success rates of dental implants have been reported as 90 to $95 \%{ }^{26,27}$ The factors associated with decreased stability and success rate for such fixtures have been widely studied and discussed. Conversely, mini-screws have not reached these high rates of success, despite the shorter usage period. ${ }^{8}$ Table 6 shows success rates reported for mini-screws used in seven different studies. It is quite possible that the factors affecting dental implant stability might not be the same as those associated with the TAD stability. Some reports on TADs indicated removal as a result of excessive mobility occurring before or during orthodontic force application. ${ }^{8}$

Motoyoshi et al suggested that an adequate IPT exists and that may be used to predict success of the mini-screws. ${ }^{11}$ Initial stability may not be achieved if the IPT is too low. If the IPT is too high, primary stability may be achieved, while osseointegration may be compromised as a result of stress surrounding the mini-screw threads, contributing to ischemic necrosis of the bone investing the mini-screw. ${ }^{11,28}$ In the Motoyoshi et al study, the mean IPT of the successful mini-screws ranged from 7.2 to $13.5 \mathrm{Ncm}$ (mean of $9 \mathrm{Ncm}$ ) depending on the location of the mini-screws. A significant difference was reported between maxillary $(8.3 \mathrm{Ncm})$ and mandibular $(10 \mathrm{Ncm})$ values. According to Motoyoshi et al, IPT values of the failure group were significantly greater than that of the success group. The only exception to this finding was for the group in which the IPT values were below $5 \mathrm{Ncm} .{ }^{11}$ In a human cadaver study, O'Sullivan et al reported insertion torques ranging from 9.6 to $26 \mathrm{Ncm}$ depending on implant types. The IPT values in this study ranged between 4.4 and $25.2 \mathrm{Ncm}$. Friberg et al noted that cutting torque was greater in the mandible than in the maxilla, attributing this finding to the presence of more compact and cortical bone in the mandible than maxilla. ${ }^{29}$ Friberg et al also found that

Table 4: Implant placement torque mean values at the 3rd turn of the mini-screw at placement. Analysis including groups I, II and III

\begin{tabular}{ll}
\hline Groups I, II and III & $\begin{array}{l}\text { Implant placement torque at } \\
\text { the 3rd turn }\end{array}$ \\
\cline { 2 - 2 } & Mean $\pm S D(\mathrm{Ncm})$ \\
\hline $\begin{array}{l}\text { Failed mini-screws } \\
(\mathrm{n}=16)\end{array}$ & $14.03 \pm 7.39$ \\
$\begin{array}{l}\text { Successful mini-screws } \\
(\mathrm{n}=12)\end{array}$ & $5.56 \pm 6.75$ \\
\hline
\end{tabular}

Student t-test; Group I: Control group; Group II: Additional control group; Group III: Test group; *Difference between the successful and failed mini-screws was significant for mean IPT at the 3rd turns at mini-screw placement $(p<0.01)$ 
the majority of failures occurred at sites with in mediumto-high-density bone. ${ }^{30}$ In the present study, there was no statistically significant difference between the mean terminal IPT values for the successful and failed mini-screws (mean of 19.76 and $21.3 \mathrm{Ncm}$ respectively). The higher mean terminal IPT values in our study could also account for the lower success rates reported.

Table 4 shows the IPT value recorded at the 3 rd turn of the mini-screw at placement was highly indicative of success or failure. The difference between the mean IPT values at this revolution in the successful and failed miniscrews (5.56 and $14.03 \mathrm{Ncm}$ respectively) was statistical significant at $p<0.01$ despite the small number of cases. This finding could represent that the torque value recorded during initial engagement of the self-drilling mini-screw to the cortical bone may be critical to success. The thread pitch in the mini-screw used in the current study is $0.762 \mathrm{~mm}$, thus three revolutions $(2.28 \mathrm{~mm})$ may correspond to the engagement of the mini-screw into the bone cortical. The IPT values at the 3rd turn during mini-screw placement for the successful mini-screws in the present study are in agreement with the values found in the group with greatest success in the study by Motoyoshi et al. ${ }^{11}$

Chen et al measured the removal torques values in miniscrews that had been used for anchorage during various types of orthodontic movement. Removal torque has long been considered an indicator of the extent of osseointegration in dental implant research and it has been suggested

Table 5: Terminal pilot drill torque mean values and mean number of turns in the successful and failed mini-screws. Analysis including groups I, II and III

\begin{tabular}{llll}
\hline Groups I, II and III & $\begin{array}{l}\text { Terminal pilot } \\
\text { drill torque }\end{array}$ & Number of turns \\
\cline { 2 - 2 } & Mean $\pm S D(\mathrm{Ncm})$ & Mean $\pm S D$ \\
\hline $\begin{array}{l}\text { Failed mini-screws } \\
(\mathrm{n}=16)\end{array}$ & $11.13 \pm 4.39$ & & $32.89 \pm 26.38$ \\
$\begin{array}{l}\text { Successful mini- } \\
\text { screws }(\mathrm{n}=12)\end{array}$ & $9.37 \pm 2.69$ & $50.00 \pm 27.37$ \\
\hline
\end{tabular}

Student t-test; Group I: Control group; Group II: Additional control group; Group III: Test group; Difference between the successful and failed mini-screws was not significant for the mean pilot drill torque values and mean number of pilot drill turns that osseointegrated implants should have a removal torque greater than $20 \mathrm{Ncm} .{ }^{31}$ In the Chen et al study, the mean mini-screw removal torque reported was $11.0 \mathrm{Ncm}$ (2.4 to $21.5 \mathrm{Ncm}$ ) and $50 \%$ of the mini-screws had removal torque values greater than $8.7 \mathrm{Ncm}$. Even though the values are lower when compared to dental implants, all the mini-screws were able to fulfill their function to provide anchorage for various types of orthodontic treatment. In the current study, all 15 successful mini-screws (7 from group I and 8 from group II) were removed at torque values less than $10 \mathrm{Ncm}$.

Cheng et al, Tseng et al, Chen et al and Kuroda et al found that mini-screws placed in the posterior human mandible were significantly more prone to failure than those placed in other areas in the mouth. ${ }^{9,23,24,32}$ Conversely, Miyawaki et al and Motoyoshi et al found no significant difference in the success rates between mandible and maxilla sites in their patient population. A definitive reason for lower success rates in the posterior mandible remains unclear. In a study of human subjects, Kuroda et al (2007) observed that the posterior mandible has less attached gingiva and a shallow vestibule. The authors speculated that this could result in less effective oral hygiene, placing contiguous tissues at the miniscrew sites at greater risk for infection. Bone in the posterior mandible is dense and overheating is more likely to occur during the screw placement. ${ }^{9}$ Overheating can not be ruled out as a factor for the high failure rates in the current study, especially if a mini-screw could not be self-drilled to depth, was backed out, and a pilot hole drilled at the same site for subsequent placement of the mini-screw (group II, where all mini-screws failed). In a situation where a mini-screw cannot be placed to depth, it may be better to use another site instead of trying to use the same site.

Some studies did not find length to be a significant factor for the success rate of mini-screws. ${ }^{8,9}$ A study by Tseng et al noted that increased screw length provided better success rates $(80 \%$ for $8 \mathrm{~mm}, 90 \%$ for $10 \mathrm{~mm}$, and $100 \%$ for 12 and $14 \mathrm{~mm}){ }^{24}$ Eighty percent was the same success rate found in the current study for $8 \mathrm{~mm}$ screw in the group III (test group-no pilot hole). Chen et al also reported an association between mini-screw length and higher rates of success

Table 6: Success rates and factors associated with failures in different studies

\begin{tabular}{|c|c|c|}
\hline Study & Success rates & Factors associated with failure \\
\hline Deguchi et al $2003^{42}$ (dogs) & $97 \%$ & All failures in the mandible and non-loaded, site between PM \\
\hline Miyawaki et al $2003^{8}$ & $0,83.9,85 \%$ ( $\varnothing$ of $1,1.5$ and $2.3 \mathrm{~mm}$ ) & Diameter of screw $(<1 \mathrm{~mm})$, inflammation, thin cortical bone \\
\hline Cheng et al $2004^{9}$ & $89 \%$ & Location (posterior mandible), type of peri-implant soft tissue \\
\hline Motoyoshi et al $2006^{11}$ & $85.5 \%$ & IPT values lower than 5 or higher than $10 \mathrm{Ncm}$ \\
\hline Chen et al $2006^{23}$ & $84.7 \%$ & $\begin{array}{l}\text { Location (md: } 81.3 \% \text {; max: } 86 \% \text { ); length ( } 8 \mathrm{~mm} \text { : } 90 \% \text {; } 6 \mathrm{~mm} \text { : } \\
72.2 \% \text { ) }\end{array}$ \\
\hline Tseng et al $2006^{24}$ & $91.1 \%$ & Location (posterior mandible), mini-implants length \\
\hline Kuroda et al $2007^{32}$ & $\begin{array}{l}81.1 \% \text { for type } A(\varnothing \text { of } 2 \text { and } 2.3 \mathrm{~mm}) \\
88.6 \% \text { for type } B(\varnothing \text { of } 1.3 \mathrm{~mm})\end{array}$ & Type B: used for intrusion, molar area \\
\hline
\end{tabular}


(success rate was $90.2 \%$ in $8 \mathrm{~mm}$ and $72.2 \%$ in $6 \mathrm{~mm}$ micro-screws). ${ }^{23}$ In the present study, the number of turns performed during mini-screw placement (measured by the drilling equipment) was statistically significant associated with success when all groups were included in the analysis. When the additional controls sites (group II) were excluded from the analysis, this difference was no longer significant, although a trend persisted. The lack of significance in the latter analysis could be explained by the small sample size. However, if a mini-screw performed 6 to 8 turns to seat, $90 \%$ succeeded. Number of turns performed by the screw during its placement suggests that a proportionally greater percentage of screw length was inserted into bone (depth of insertion), thus providing a better primary stability. The thread pitch in the mini-screw used in the current study is $0.762 \mathrm{~mm}$. Thus, eight turns performed by the mini-screw could imply that $\sim 6 \mathrm{~mm}$ of the mini-screw penetrated the bone as long as there was constant engagement. Tseng et al recommended that mini-screw depth into bone should be at least $6 \mathrm{~mm} .{ }^{24}$ Deguchi et al stated that bone quantity is a major factor in the stability of the mini-screws since their stability could be achieved by mechanical interdigitation rather than osseointegration during the early stages of healing. ${ }^{33}$

The fact that the implants in this study were not loaded may have been a factor for the low success rate found in this study. Fritz et al reported more pronounced osteodynamic activity in vertically-loaded mini-screws than in horizontallyloaded implants, suggesting that the peri-implant bone may perceive the orthodontic loading as a stimulus and adapt to its stress by remodeling. ${ }^{34}$ This was also suggested by Wehrbein et al who hypothesized that the remodeling activity of the adjacent bone increased with increasing load. ${ }^{35}$ Ohmae et al also observed that the bone activity was higher in the cervical area than in other areas of loaded implants. ${ }^{18}$ Therefore, immediate loading may have contributed to a better prognosis of the mini-screws used in the present study. One study suggested that immediate loading was possible and did not adversely impact stability or success rate of the screws as long as the load-related biomechanics do not exceed an upper limit of tipping movement at the bone rim. However, the amount of stress and strain is dependent on the geometry of the screw and the mechanical properties of the implant and the bone. ${ }^{36}$ Another study concluded that tapered-screws could tolerate immediate loading and achieve stable anchorage, whereas straight-screws needed a sufficient healing period since the amount of bone-screw contact increased significantly from 2 to 8 weeks. ${ }^{19}$ Motoyoshi et al also concluded that taper-shaped mini-screws could endure immediate loading as result of their initial stability and rigid mechanical contact between the implant and bone. ${ }^{11}$ The mini-screws used in the current study had a tapered design.
The optimal healing time for mini-screws used for orthodontic anchorage is still controversial, with authors suggesting different healing times in their designs. Some authors have used immediate loading, ${ }^{36}$ while other authors have recommended various healing periods, such as 2 weeks ${ }^{6,23,24}$ 6 weeks, ${ }^{18} 18$ weeks, ${ }^{37}$ and 6 months. ${ }^{34}$ It appears that 2 to 3 weeks of healing is probably be the worst time for loading since osteoclastic activity after injury reaches its peak during this time. ${ }^{38}$ In cases where dental implants are used as abutments, immediate loading and delayed loading implants have achieved comparable success rates, suggesting that there is no adverse effect on new bone formation and bone-to-implant contact. ${ }^{39,40}$ Regarding dental implants, the crucial prerequisite for immediate loading is primary stability which seems to minimize distortional strains and improve bone regeneration at the peri-implant interface. It is possible that the mini-screws used for temporary orthodontic anchorage could withstand immediate loading if they were placed in good-quality bone and achieved primary stability. It is suggested that a waiting period for bone healing and osseointegration before loading is unnecessary because the primary stability (mechanical retention) of the TADs would be sufficient to bear a normal orthodontic loading. ${ }^{41}$ This matter should, however, be investigated in a specific investigation since loading and time of loading was not part of the current study.

Greater primary stability may be related to decreased micromotion, allowing for a better healing environment. Another factor associated with implant failure is movement during healing-micromotion (up to $28 \mu \mathrm{m}$ ), which is design and load dependent, has no adverse effect on osteointegration and does not systematically lead to fibrous tissue interposition. ${ }^{40}$ However, uncontrolled mastication forces, which can occur especially in animal trials like the present study, can result in parafunctional forces that could interfere with the initial healing process around fixtures. Some mini-screws in this study were lost possibly due to physical trauma caused by the animals chewing on their cage. Some of the animals had silver marks on their teeth suggesting that they had been chewing on the aluminum bars in their cages. The high failure rates found in this study compared to others may have been the result of by parafunctional forces (chewing the cage), such as that clearly evidenced in some of animals in this study.

A study by Deguchi et al reported that the greatest number of failures occurred in the group in which the mini-screws were placed between the roots of the first and second premolars. The authors mentioned that the failures could have been caused by anatomical limitations on the site. Since this site was the narrowest of all the surgical sites, the reason for failure may be associated with a surgical problem related to 
encroachment to the roots of the adjacent teeth. ${ }^{42}$ Although this site specifically was not used in the present study, all the mini-screws were placed between the roots in limited and narrow interradicular spaces, making the surgical procedure technically difficult. ${ }^{32}$ This may also account for the high failure rate reported here. However, in the current study, when radiographically comparing the mini-screws that were placed within $1 \mathrm{~mm}$ of or more than $1 \mathrm{~mm}$ from the roots of the teeth, no trend could be found in the success/failure rates. It should be emphasized that the radiographs used in this study were not geometrically standardized, so definitive conclusions should not be drawn. The interradicular sites were chosen in order to allow placement in keratinized/ attached tissue. This would minimize soft tissue irritation, which often occurs seen when the devices are placed in non-keratinized mucosa. ${ }^{9,32}$

Currently, no data is available on the distance necessary between the mini-screws and the roots of teeth in order to preserve periodontal integrity and mini-screw stability. It is assumed that a minimum clearance of $1 \mathrm{~mm}$ of alveolar bone around the screw might be sufficient to maintain periodontal health. ${ }^{43}$ Even though proximity of the screws with the roots of the teeth may be associated with failure, apparently a screw encroachment on the root may not be of clinical significance. Fabbroni et al evaluated titanium transalveolar screws (with a $2 \mathrm{~mm}$ diameter) used for intermaxillary fixation and reported that $11.2 \%$ of the screws had major contact (more than $50 \%$ of the diameter of the screw hole) and $15.9 \%$ had minor contact (less than $50 \%$ of the diameter of the screw hole) with adjacent tooth roots. Only 17 of the 440 screw-adjacent teeth presented as non-vital at the time of screw removal. Of these 17 , only six had some sort of radiographic encroachment. ${ }^{44}$ This area needs to be further evaluated with studies analyzing mini-screws specifically placed for orthodontic anchorage. Nonetheless, it is highly recommended that a thorough evaluation of the relationship of the site and insertion pathway of the mini-screws placement with adjacent anatomic structures be completed in order to minimize as much as possible any iatrogenic damage.

Inflammation of the soft tissue was noted around some of the mini-screws present at the time of removal (6 weeks). One could conclude that mini-screw stability might be at risk due to presence of inflammatory involvement of the surrounding tissues. Cheng et al suggested that peri-implant infection was associated with a high rate of implant failure, since peri-implant infection was found at seven implants, five of which failed (i.e, $71 \%$ failure rate with peri-implant infection). ${ }^{9}$ Tseng et al also agreed that inflammation in the tissues around the mini-screws could hasten their loss. ${ }^{24}$ Although, it was not quantified in this study how the soft tissue inflammation could have influenced the success rate of the mini-screws, it seems reasonable to assume that effective plaque control at the mini-screw neck/soft tissue interface would increase success rates. This may be facilitated by mechanical cleansing and the use of antimicrobial mouthrinses applied topically/locally or as a rinse.

\section{CONCLUSION}

There was no statistically significant difference in the success rate between the group that used a pilot drill (46\%) and the group that did not $(80 \%)$. There was no statistically significant difference in the mean terminal IPT values and the mean number of turns for failed and successful selfdrilling mini-screws. However, if a self-drilling mini-screw performed 6 to 8 turns to seat, $90 \%$ succeeded. The difference between the mean IPT values at the 3rd turn during self-drilling mini-screw insertion in the successful and failed mini-screws (5.56 and $14.03 \mathrm{Ncm}$ respectively) was statistically significant. This finding could indicate that the torque value encountered during initial cortical bone engagement of the self-drilling mini-screw may be critical to success.

\section{ACKNOWLEDGMENTS}

Authors would like to thank OsteoMed (OsteoMed Corporation, Addison, TX) for providing the $\mathrm{OMI}^{\mathrm{TM}}$ (Orthodontic Anchor System) and mini-screws for this study.

\section{REFERENCES}

1. Cope JB. Temporary anchorage devices in orthodontics: a paradigm shift. Semin Orthod 2005;11:3-9.

2. Mah J, Bergstrand F. Temporary anchorage devices: a status report. J Clin Orthod 2005 Mar;39(3):132-136.

3. Huang HM, Chiu CL, Yeh CY, Lee SY. Factors influencing the resonance frequency of dental implants. J Oral Maxillofac Surg 2003 Oct;61(10):1184-1188.

4. Roberts W, Marshall K, Mosary P. Rigid endosseous implant utilized as anchorage to protract molars and close an atrophic extraction site. Angle Orthod 1990;60:135-152.

5. Kanomi R. Mini-implant for orthodontic anchorage. J Clin Orthod 1997 Nov;31(11):763-767.

6. Liou EJ, Pai BC, Lin JC. Do mini-screws remain stationary under orthodontic forces? Am J Orthod Dentofacial Orthop 2004 Jul;126(1):42-47.

7. Huang LH, Shotwell JL, Wang HL. Dental implants for orthodontic anchorage. Am J Orthod Dentofacial Orthop 2005 Jun; 127(6):713-722.

8. Miyawaki S, Koyama I, Inoue M, Mishima K, Sugahara T, TakanoYamamoto T. Factors associated with the stability of titanium screws placed in the posterior region for orthodontic anchorage. Am J Orthod Dentofacial Orthop 2003 Oct;124(4):373-378.

9. Cheng SJ, Tseng IY, Lee JJ, Kok SH. A prospective study of the risk factors associated with failure of mini-implants used for orthodontic anchorage. Int J Oral Maxillofac Implants 2004 Jan-Feb;19(1):100-106.

10. Friberg B, Sennerby L, Linden B, Grondahl K, Lekholm U. Stability measurements of one-stage Brånemark implants during 
healing in mandibles. A clinical resonance frequency analysis study. Int J Oral Maxillofac Surg 1999 Aug;28(4):266-272.

11. Motoyoshi M, Hirabayashi M, Uemura M, Shimizu N. Recommended placement torque when tightening an orthodontic miniimplant. Clin Oral Implants Res 2006 Feb;17(1):109-114.

12. Motoyoshi M, Yano S, Tsuruoka T, Shimizu N. Biomechanical effect of abutment on stability of orthodontic mini-implant. A finite element analysis. Clin Oral Implants Res 2005 Aug;16(4): 480-485.

13. Chen YJ, Chen YH, Lin LD, Yao CC. Removal torque of miniscrews used for orthodontic anchorage - a preliminary report. Int J Oral Maxillofac Implants 2006 Mar-Apr;21(2):283-289.

14. Kravitz ND, Kusnoto B. Placement of mini-implants with topical anesthetic. J Clin Orthod 2006 Oct;40(10):602-604.

15. Melsen B, Verna C. Miniscrew implants: the Aarhus anchorage system. Semin Orthod 2005;11:24-31.

16. Swoden D, Schmitz JP. AO self-drilling and self-tapping screws in rat calvarial bone: an ultrastructural study of the imlant interface. J Oral Maxillofac Surg 2002;60:294-299.

17. Heidemann W, Gerlach KL. Clinical applications of drill free screws in maxillofacial surgery. J Craniomaxillofac Surg 1999 Aug;27(4):252-255.

18. Ohmae M, Saito S, Morohashi T, Seki K, Qu H, Kanomi R, et al. A clinical and histological evaluation of titanium mini-implants as anchors for orthodontic intrusion in the beagle dog. Am J Orthod Dentofacial Orthop 2001 May;119(5):489-497.

19. Yano S, Motoyoshi M, Uemura M, Ono A, Shimizu N. Tapered orthodontic miniscrew induce bone-screw cohesion following immediate loading. Eur J Orthod 2006;28:541-546.

20. Heidemann W, Terheyden H, Gerlach KL. Analysis of the osseous/metal interface of drill free screws and self-tapping screws. J Craniomaxillofac Surg 2001 Apr;29(2):69-74.

21. Albrektsson T, Zarb G, Worthington P, Eriksson A. The long-term efficacy of currently used dental implants: a review and proposed criteria of success. Int J Oral Maxillofac Implants 1986;1:11-25.

22. Huja SS, Litsky AS, Beck FM, Johnson KA, Larsen PE. Pullout strength of monocortical screws placed in the maxillae and mandibles of dogs. Am J Orthod Dentofacial Orthop 2005 Mar; 127(3):307-313.

23. Chen $\mathrm{CH}$, Chang CS, Hsieh CH, Tseng YC, Shen YS, Huang IY, et al. The use of microimplants in orthodontic anchorage. J Oral Maxillofac Surg 2006 Aug;64(8):1209-1213.

24. Tseng YC, Hsieh CH, Chen CH, Shen YS, Huang IY, Chen CM. The application of mini-implants for orthodontic anchorage. Int J Oral Maxillofac Surg 2006 Aug;35(8):704-707.

25. Freudenthaler J, Hass R, Bantleon H. Bicortical titanium screws for the critical orthodontic anchorage in the mandible: a preliminary report on clinical applications. Clin Oral Implants Res 2001;12(4):358-363.

26. Adell R, Lekholm U, Rocher B, Brånemark P. A 15-year study of the edentulous jaw. Int J Oral Surg 1981;10:387-416.

27. Albrektsonn T, Branemark P, Hasson H, Lindstron J. Titanium implant. Requirements for ensuring a long-lasting direct bone anchorage in man. Acta Orthop Scand 1981;52:155-170.

28. Meredith N. Assessment of implant stability as a prognostic determinant. Int J Prosthodont 1998 Sep-Oct;11(5):491-501.
29. Friberg B, Sennerby L, Grondahl K, Bergstrom C, Back T, Lekholm U. On cutting torque measurements during implant placement: a 3-year clinical prospective study. Clinical Implant Dentistry and Related Research 1999;1:75-83.

30. Friberg B, Sennerby L, Roos J, Lekholm U. Identification of the bone quality in conjunction with insertion of titanium implants: a pilot study in jaw autopsy specimens. Clin Oral Implants Res 1995;6:213-219.

31. Sullivan D, Sherwood R, Collins T, Krogh P. The reverse torque test: a clinical report. Int J Oral Maxillofac Implants 1996;11:179-185.

32. Kuroda S, Sugawara Y, Deguchi T, Kyung HM, TakanoYamamoto T. Clinical Use of miniscrews implants as orthodontic anchorage: Success rates and postoperative discomfort. Am J Orthod Dentofacial Orthop 2007;131:9-15.

33. Deguchi T, Nasu M, Murakami K, Yabuuchi T, Kamioka H, Takano-Yamamoto T. Quantitative evaluation of cortical bone thickness with computed tomographic scanning for orthodontic implants. Am J Orthod Dentofacial Orthop 2006 Jun;129(6): 721-727.

34. Fritz U, Diedrich P, Kinzinger G, Al-Said M. The anchorage quality of mini-implants towards translatory and extrusive forces. J Orofac Orthop 2003 Jul;64(4):293-304.

35. Wehrbein H, Merz BR. Aspects of the use of endosseous palatal implants in orthodontic therapy. J Esthet Dent 1998;10(6): 315-324.

36. Buchter A, Wiechmann D, Koerdt S, Wiesmann HP, Piffko J, Meyer U. Load-related implant reaction of mini-implants used for orthodontic anchorage. Clin Oral Implants Res 2005 Aug; 16(4):473-479.

37. Saito S, Sugimoto N, Morohashi T. Rigid endosseous implants for orthodontic and orthopedic anchorage. Angle Orthod 1989;59:247-256.

38. Asscherickx K, Vannet BV, Wehrbein H, Sabzevar MM. Root repair after injury from mini-screw. Clin Oral Implants Res 2005 Oct;16(5):575-578.

39. Nkenke E, Hahn M, Weinzierl K, Radespiel-Troger M, Neukam FW, Engelke K. Implant stability and histomorphometry: a correlation study in human cadavers using stepped cylinder implants. Clin Oral Implants Res 2003 Oct;14(5):601-609.

40. Szmukler-Moncler S, Salama S, Reingewirtz Y, Dubruille JH. timing of loading and effect of micro-motion on bone-implant interface: a review of experimental literature. J Biomed Mater Res 1998;43:193-203.

41. Costa A, Raffainl M, Melsen B. Mini-screws as orthodontic anchorage: a preliminary report. Int J Adult Orthod Orthognath Surg 1998;13(3):201-209.

42. Deguchi T, Takano-Yamamoto T, Kanoni R Jr JKH, WE R, Garetto L. The use of small titanium screws for orthodontic anchorage. J Dent Res 2003;82(5):377-381.

43. Poggio PM, Incorvati C, Velo S, Carano A. Safe zones: a guide for miniscrew positioning in the maxillary and mandibular arch. Angle Orthod 2006 Mar;76(2):191-197.

44. Fabbroni G, Aabed S, Mizen K, Starr D. Transaveolar screws and the incidence of dental damage: a prospective study. Int $\mathrm{J}$ Oral Maxillofac Implants 2004;33:442-446. 